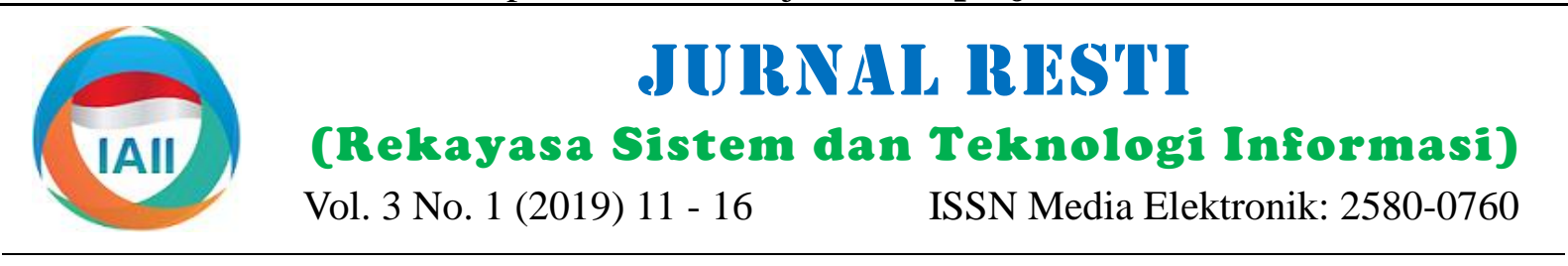

\title{
Pendeteksi Volume Air Secara Otomatis Menggunakan Fuzzy
}

\author{
Ipriadi $^{1}$, Gunadi Widi Nurcahyo ${ }^{2}$, Julius Santony ${ }^{3}$ \\ ${ }^{123}$ Fakultas Ilmu Komputer, Universitas Putra Indonesia "YPTK" Padang \\ 1'ipriadi8@gmail.com, ${ }^{2}$ gunadiwidi@gmail.com, ${ }^{3}$ juliussantony@ upiyptk.ac.id
}

\begin{abstract}
The availability of water in a building or building is still difficult to monitor, because the method used still relies on humans. Helps in detecting the volume of water effectively in water reservoirs using ultrasonic hc-sr04 sensors and fuzzy logic. The availability of water in a building or building is monitored when the water in the shelter has run out. This is not good because the availability of water is very necessary and must meet building needs continuously. During this time, monitoring the volume of water storage is done visually. the water is from the top only, so that the information obtained is not accurate. In addition, the container is generally not transparent. So it is difficult to monitor the volume of the water tank. In designing this tool the system is able to work accurately with high input water and the output of tap water using water flow sensors and testing on matlap can determine the fill level seen from the designed rules. The results of the detection of ultrasonic sensors are three led indicator signs, leds blue indicates that the volume of water in the water tank is full, the yellow led member knows that the water tank is partially filled and the red led tells that the volume of water in the water tank has run out and is immediately replenished. From the results of this test, conclusions can be drawn in determining the level status
\end{abstract}

Keywords: Ultrasonik Hc-sr04,Water flow, Fuzzy Logic

\begin{abstract}
Abstrak
Ketersediaan air di suatu gedung atau bangunan masih sulit untuk dipantau, karena cara yang digunakan masih mengandalkan manusia. Membantu dalam memdeteksi volume air secara efektif pada bak penampungan air menggunakan sensor ultrasonic hc-sr04 dan fuzzy logic. Ketersediaan air di suatu gedung atau bangunan dipantau saat air pada penampungan telah habis.Hal ini tidak baik karena ketersediaan air sangat perlu dan harus mencukupi kebutuhan gedung secara terus-menerus.Selama ini, pemantauan volume penampungan air dilakukan secara visual.Seseorang hanya melihat isi penampungan air tersebut dari bagian atas saja, sehingga informasi yang didapat tidak akurat.Selain itu, wadah penampungan umumnya tidak tembus pandang.Sehingga sulit untuk dilakukan pemantauan volume tanki air. Pada perancangan alat ini system mampu bekerja secara akurat dengan input tinggi air dan keluaran air kran menggunakan sensor water flow serta pengujian pada matlap dapat menentukan tingkat pengisian yang dilihat dari rule-rule yang dirancang.Hasil dari pendeteksian sensor ultrasonic terdapat tiga tanda led indicator,led biru menandakan bahwa volume air didalam water tank sudah penuh,led kuning membertahu bahwa water tank sebagian terisi dan led warna merah memberitahukan bahwa volume air didalam water tank sudah habis dan segera diisi kembali. Dari hasil pengujian ini,dapat diambil kesimpulan dalam penentuan status tingkat.
\end{abstract}

Kata kunci: Ultrasonik Hc-sr04,Water flow, Fuzzy Logic

(C) 2019 Jurnal RESTI

\section{Pendahuluan}

Dalam kehidupan sehari-hari sering kali hal terkecil yang dilakukan oleh manusia baik dalam pemanfaatan air bersih sangat tergantung pada teknologi zaman sekarang, seperti halnya mesin pompa air atau alat penyedot air, namun sering kali manusia tidak bisa mengontrol sepenuhnya penggunaan teknologi tersebut, mengakibatkan kelebihan jumlah volume air tidak sesuai dengan ukuran tangki air .Dunia dan masyarakat kita menghadapi penggunaan air yang berlebihan baik untuk tujuan domestik maupun komersial dan itu adalah hal yang serius yang mempengaruhi keberlanjutan lingkungan kita. Kelangkaan air yang disebabkan oleh arus perubahan iklim, seperti pola cuaca yang berubah (termasuk kekeringan atau banjir) meningkatnya polusi dan peningkatan manusia permintaan dan penggunaan air secara berlebihan [1].

Diterima Redaksi : 03-01-2019 | Selesai Revisi : 17-03-2019| Diterbitkan Online : 30-04-2019 
Namun demikian ada hal-hal yang harus kita memberikan input berupa tinggi air dan keluaran air perhatikan saat menggunakan air dalam segi kran kemudian Fuzzyfikasi Merupakan tahap yang (kehematan). Hal ini tidak lain karena air sangat harus ada dalam logika fuzzy. Pada Metode Mamdani, diperlukan dalam kehidupan manusia dan mahkluk baik variabel input maupun variabel output dibagi hidup lainnya. Oleh karena itu suatu mekanisme deteksi menjadi satu atau lebih himpunan Fuzzy. Dalam dini terhadap volume air sangat diperlukan untuk penentuan tingkat pengisian dengan parameter tingkat menghindari pemborosan air baik bagi manusia atau pengisian volume air, variabel input dibagi menjadi dua tumbuhan dan hewan. Sudah banyak penelitian yang yaitu variabel air dan kran. Sedangkan variabel output membahas tentang pendeteksi volume air pada tangki hanya satu, yaitu variabel tingkat pengisian volume air. air.

Salah satunya penelitian yang membahas bagaimana sistem pengendali otomatis sensor volume air [1]. Fuzzy Logic banyak digunakan dalam berbagai macam penelitian seperti pada penelitian sebelumnya menggunakan MATLAB yang digunakan untuk deteksi Tingkat Air Otomatis dan Aplikasi untuk tangki pengisian air terbuka untuk AC Pusat[2]. Penerapan logika Fuzy aplikasi tentang Tangki air cerdas berbasis IoT [3]. Sistem Pendukung Keputusan berbasis Fuzzy Logic untuk Smart Pemantauan dan Pengendalian Tangki Air [4]. Optimalisasi desain fungsi keanggotaan untuk tangki air menggunakan fuzzy logic [5]. Perancangan Sistem buka tutup pintu air otomatis dimuara/waduk menggunakan sensor infrared dan photodioda dengan tampilan LCD berbasis arduino uno Atemega-328 [6]. Perancangan kontroler Fuzzy Logic untuk Pengendalian Level Cairan [7].Sistem Pendeteksi Dini Banjir Menggunakan Sensor Kecepatan Air dan Sensor Ketinggian Air pada Mikrokontroler Arduino [8]. Desain sistem pemantauan tangki air berbasis perangkat seluler, konferensi internasional tentang mekatronik, elektronik, dan rekayasa otomotif [9]. fuzzy expert system penyakit scabies pada kambing [10]. Pada penelitian ini akan dijelaskan perancangan alat pendeteksi volume air pada tangki air dengan menerapkan metode Fuzzy Logic memanfaatkan sensor ultrasonic HC-SR04, dengan diterapkannya metode Fuzzy Logic ini diharapkan bisa membantu dalam memantau dan mengontrol volume air pada tangki air. Pada perancangan sistem ini, penulis menggunakan algoritma Fuzzy Logic dengan metode mamdani sehingga dapat mempermudah dalam memperoleh hasil yang sesuai dengan perhitungan tingkat keakuratan sensor.

\section{Metode Penelitian}

Pada gambar 1 merupakan gambar dari flowchart logika fuzzy yang akan mempermudah dalam proses pembuatan program. Berikut akan dijelaskan tahapantahapan pada flowchart program : Initialisasi Port yaitu merupakan tahap untuk sudah didapatkan maka ini adalah tahap akhir dari memperkenalkan port-port yang akan digunakan, flowchart program. Jika kondisi true maka proses akan seperti port pada sensor. Pada tahap baca Sensor berhenti, Jika false maka proses otomatis akan looping. Ultrasonik dan Water flow tahap ini sensor ultrasonik dan water flow merupakan sensor yang berperan sebagai input. Sensor inilah yang nantinya akan

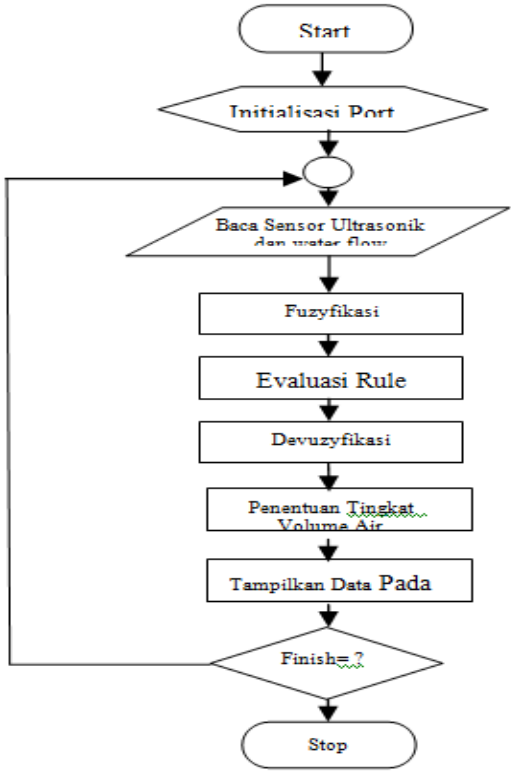

Gambar 1. Flowchart Metode Logika Fuzzy

Evaluasi Rule Setelah melalui tahap Fuzzifikasi maka tahap selanjutnya adalah Evaluasi Rule. Pada tahap ini akan ditentukan rule-rule yang akan dipakai lalu Defuzzifikasimerupakan tahap akhir dari metode mamdani. Input dari proses Defuzzifikasi adalah suatu himpunan Fuzzy yang diperoleh dari komposisi aturan Fuzzy, sedangkan output yang dihasilkan merupakan suatu bilangan tegas pada domain himpunan Fuzzy tersebut. Sehingga jika diberikan suatu himpunan Fuzzy dalam range tertentu, maka harus dapat diambil suatu nilai crisp tertentu sebagai output.

Penentuan Tingkat Pengisian tangki air Pada tahap ini merupakan tahap untuk menentukan status tingkat pengisian secara normal. Hasil didapatkan berdasarkan dari pendeteksian pada alat dan perhitungan menggunakan aplikasi matlab 7.1 kemudian tampilkan Data Hasil Pendeteksian Ke LCD 2X16 Setelah proses di atas dilakukan, maka pada tahap ini hasil Tingkat engisian secara normal akir Finish / Stop Jika hasil pengisian secara normal Akan ditampilkan pada LCD

Jurnal RESTI (Rekayasa Sistem dan Teknologi Informasi) Vol. 3 No. 1 (2019) 11- 16 


\section{Hasil dan Pembahasan}

Rancangan fisik alat secara umum,,rancangan fisik alat ini dapat dikelompokkan beberapa bagian yang terdiri dari : Modul arduino uno, Sensor ultrasonic Sensor water flow, mesin pompa air dan rangkaian power supply. Bentuk rancangan fisik Alat dapat dilihat pada gambar 2 di bawah ini.

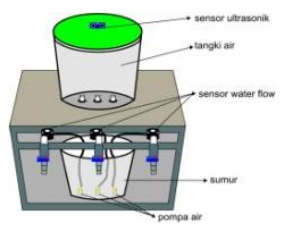

Gambar 2.Rancangan Fisik Alat

Desain dari alat yang dibuat merupakan gambaran dari alat secara keseluruhan. Dengan adanya desain alat ini, maka prinsip kerja dari alat serta komponen-komponen dari sistem yang digunakan akan dapat dilihat dengan jelas.

Rangkaian Sensor Ultrasonik berfungsi untuk mendeteksi ketinggian pada tangki air. Rangkaian Sensor ultrasonic dapat dilihat pada gambar 3 .

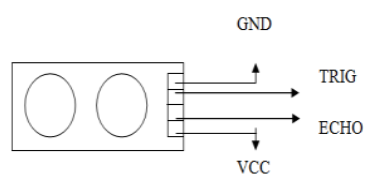

Gambar 3. Rangkaian Sensor Ultrasonik

sehingga mendapatkan output berupa pemberitahuan tingkat volume. Dalam penentuan status tingkat volume digunakan metode Mamdani atau sering juga dikenal dengan nama Metode Min - Max. Untuk mendapatkan output, diperlukan empat tahapan yaitu Pembentukan himpunan Fuzzy, aplikasi fungsi implikasi, komposisi aturan, penegasan (defuzzifikasi). Identifikasi untuk menentukan tingkat volume dilakukan dengan menentukan variabel yang diperlukan dalam pengolahan dan analisis, di mana variabel yang harus dipenuhi adalah air. Yang akan disusun menjadi struktur hirarki seperti Gambar 5.

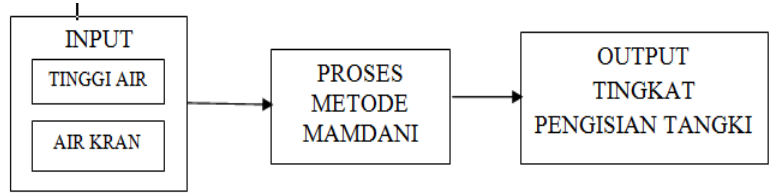

Gambar 5. Metode Logika Fuzzy

Untuk hasil pembahasan diambil dari nilai masing masing sensor.Input terdiri dar tinggi air dan air yang dikelurkan melalui kran mengguakan sensor Ultrasonic HC-SR04.Untuk proses menggunakan metode mamdani dengan menghasilkan output untuk menentukan tingkat ketinggian air.

Tabel 1. Nilai Dari Input dan Output

\begin{tabular}{lll}
\hline \multicolumn{1}{c}{ Fungsi } & \multicolumn{1}{c}{ Nama variabel } & \multicolumn{1}{c}{$\begin{array}{c}\text { Semesta } \\
\text { pembicaraan }\end{array}$} \\
\hline Input & Tinggi air & $0-22$ \\
& Air kran & $0-100$ \\
Output & Tingkat pengisian & $0-200$ \\
\hline
\end{tabular}

Rangkaian Sensor ultrasonic digunakan untuk Nilai dari ketinggian air 0-22 cm ,untuk air melalui mengukur tingkat volume air. Tipe sensor yang kran 0-100 ml/detik dan tingkat pengisisan tangki 0digunakan yaitu sensor ultrasonic hc-sr 04.Rangkaian $200 \mathrm{ml} /$ detik.

penurun tegangan ini dibutuhkan karena Arduino Uno hanya membutuhkan tegangan +5 volt untuk Vcc sistem.Gambar rangkaian catu daya dapat dilihat pada gambar 4.

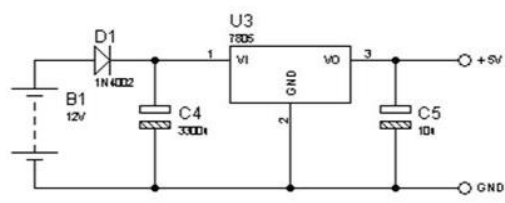

Gambar 4. Rangkaian Power Suplay

Jika tegangan pada power supply ini kurang dari $+4,5$ volt, maka mikrokontroller akan mereset kembali dan dapat membuat modul program menjadi kacau, untuk itu dibutuhkan rangkaian catu daya sebagai penurun tegangan ini untuk mendapatkan tegangan yang dibutuhkan.

Fuzzy logic dalam sistem ini berfungsi untuk menentukan tingkat pengisian volume pada tangki air. Dalam penentuan tingkat volume, aplikasi logika Fuzzy ini digunakan untuk mengubah input yang berupa air
Tabel 2.Himpunan fuzzy

\begin{tabular}{|c|c|c|c|c|}
\hline Variabel & $\begin{array}{l}\text { Himpu } \\
\text { nan }\end{array}$ & Domain & $\begin{array}{l}\text { Fungsi } \\
\text { Keanggo } \\
\text { taan }\end{array}$ & Parameter \\
\hline \multirow[t]{3}{*}{$\begin{array}{l}\text { Tinggi } \\
\text { Air }\end{array}$} & Sedikit & {$[0 ; 11]$} & $\begin{array}{l}\text { Bahu } \\
\text { Kiri }\end{array}$ & {$\left[\begin{array}{llll}0 & 0 & 2 & 11\end{array}\right]$} \\
\hline & $\begin{array}{l}\text { Seteng } \\
\text { ah }\end{array}$ & {$[6 ; 16]$} & Segitiga & {$\left[\begin{array}{lll}6 & 11 & 16\end{array}\right]$} \\
\hline & Penuh & {$[11 ; 22]$} & $\begin{array}{l}\text { Bahu } \\
\text { Kanan }\end{array}$ & {$\left[\begin{array}{llll}11 & 20 & 22 & 22\end{array}\right]$} \\
\hline \multirow[t]{2}{*}{ Air Kran } & Sedikit & {$[0 ; 50]$} & Bahu kiri & {$\left[\begin{array}{llll}0 & 0 & 10 & 50\end{array}\right]$} \\
\hline & $\begin{array}{l}\text { Sedang } \\
\text { Banyak }\end{array}$ & $\begin{array}{l}{[30 ; 70]} \\
{[50 ; 100]}\end{array}$ & $\begin{array}{l}\text { Segi tiga } \\
\text { Bahu } \\
\text { kanan }\end{array}$ & $\begin{array}{l}{\left[\begin{array}{lll}30 & 50 & 70\end{array}\right]} \\
{\left[\begin{array}{lll}50 & 85 & 100 \\
100\end{array}\right]}\end{array}$ \\
\hline \multirow{3}{*}{$\begin{array}{l}\text { Tingkat } \\
\text { pengisia } \\
\mathrm{n} \text { air }\end{array}$} & Lambat & {$[0 ; 100]$} & Bahu kiri & {$\left[\begin{array}{llll}0 & 0 & 20 & 100\end{array}\right]$} \\
\hline & Normal & {$[60 ; 140]$} & Segi tiga & {$\left[\begin{array}{lll}60 & 100 & 140\end{array}\right]$} \\
\hline & Cepat & {$[100 ; 200]$} & $\begin{array}{l}\text { Bahu } \\
\text { kanan }\end{array}$ & $\begin{array}{l}{\left[\begin{array}{lll}100 & 175 & 200 \\
200]\end{array}\right.}\end{array}$ \\
\hline
\end{tabular}

Dari tabel 2, fungsi keanggotaan yang digunakan pada penelitian ini adalah representasi kurva segitiga, bahu kiri dan bahu kanan . Fungsi keanggotaan masing-masing variabel dapat dibagi sebagai berikut: 
Himpunan Fuzzy Variabel Tinggi Air didefinisikan Rule 1 : If ( Tinggi Air is Sedikit ) and (Kran is Sedikit tiga himpunan Fuzzy, yaitu Sedikit, setengah,penuh. ) then (Tingkat Pengisian is Cepat).Variabel Tinggi Untuk merepresentasikan variabel tinggi air digunakan Air dengan tinggi $8 \mathrm{~cm}$ termasuk dalam keanggotaan bentuk kurva bahu kiri untuk himpunan Fuzzy Sedikit, sedikit, dengan perhitungan bentuk kurva segitiga untuk himpunan Fuzzy Setengah, dan bentuk kurva bahu kanan untuk himpunan Fuzzy penuh. Gambar himpunan Fuzzy untuk variabel air dapat dilihat pada Gambar 6.

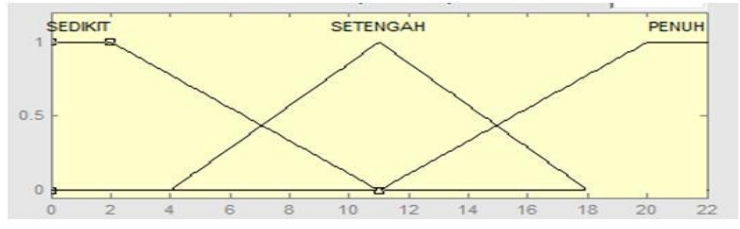

Gambar 6 Membership Fuction Untuk Variabel Tinggi Air

Himpunan Fuzzy Variabel kran didefinisikan tiga himpunan Fuzzy, yaitu sedikit, sedang dan banyak. Untuk merepresentasikan variabel kran digunakan bentuk kurva bahu kiri untuk himpunan Fuzzy Sedikit, bentuk kurva segitiga untuk himpunan Fuzzy Sedang.Bentuk kurva bahu kanan untuk himpunan Fuzzy Banyak. Representasi himpunan Fuzzy untuk variabel kran ditunjukkan pada gambar 7 .

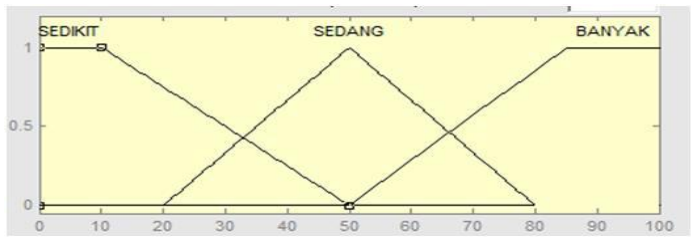

Gambar 7 Membership Fuction Untuk Variabel Air Kran

Himpunan Fuzzy Variabel Tingkat volume diperoleh berdasarkan pengukuran sensor.Pada variable tingkat pengisian volume air didefinisikan tiga himpunan Fuzzy, yaitu lambat, normal, cepat. Untuk merepresentasikan variabel tingkat volume air digunakan bentuk kurva bahu kiri untuk himpunan Fuzzy lambat, bentuk kurva segitiga untuk himpunan Fuzzy normal, bentuk kurva bahu kanan untuk himpunan Fuzzy cepat. Gambar himpunan Fuzzy untuk variabel tingkat pengisian volume air ditunjukkan pada gambar 8 .

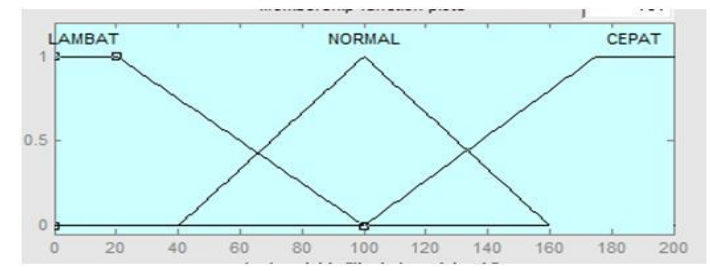

Gambar 8 Membership Fuction Untuk Variabel Tingkat Pengisian Air

$$
\begin{aligned}
& \mu \text { Sedikit }[8]=(\mathrm{d}-\mathrm{x}) /(\mathrm{d}-\mathrm{c}) \\
& =(11-\mathrm{x}) /(11-2) \\
& =(11-8) /(9) \\
& =3 / 9 \\
& =0,3
\end{aligned}
$$

Variabel dengan Air Kran $40 \mathrm{ml}$ termasuk dalam keanggotaan sedikit, dengan perhitungan

$\mu$ Sedikit $[40]=(d-x) /(d-c)$

$$
\begin{aligned}
& =(50-40) /(50-10) \\
& =(50-40) /(40) \\
& =10 / 40 \\
& =0,25
\end{aligned}
$$

Rule 2 : If (Tinggi Air is Sedikit) and (Air Kran is Sedang) then (Tingkat Pengisian is Cepat) Variabel Tinggi Air (Tinggi Air is Sedikit).

$\mu$ Sedikit $[8]=(d-x) /(d-c)$

$$
\begin{aligned}
& =(11-\mathrm{x}) /(11-2) \\
& =(11-8) /(9) \\
& =3 / 9 \\
& =0,3
\end{aligned}
$$

Variabel Air Kran (Air Kran is Sedang)

$\mu$ Sedang $[40]=(50-20) /(40-20)$

$$
\begin{aligned}
& =(30) /(20) \\
& =1,5
\end{aligned}
$$

$\mu$ Sedang $[40]=(50-40) /(80-50)$

$$
\begin{aligned}
& =(10) /(30) \\
& =0,3
\end{aligned}
$$

Rule 4 : If (Tinggi Air is Setengah) and (Air Kran is Sedikit) then (Tingkat Pengisian is Normal). Variabel Tinggi Air (Tinggi Air is Sedang).

$$
\begin{gathered}
\begin{aligned}
& \mu \text { Sedang }[8]=(11-4) /(8-4) \\
&= 7 / 6 \\
&= 1,2 \\
& \mu \text { Sedang }[8]=(11-8) /(18-11) \\
&= 3 / 7 \\
&=0,4
\end{aligned}
\end{gathered}
$$

Variabel Air Kran (Air Kran is Sedikit)

$\mu$ Sedikit $[40]=(50-40) /(50-10)$

$$
\begin{aligned}
& =(10) /(40) \\
& =0,25
\end{aligned}
$$

Rule 5 : If (Tinggi Air is Setengah) and (Air Kran is Sedang) then (Tingkat Bahaya is Normal). Variabel Tinggi Air (Tinggi Air is Sedang)

$$
\begin{aligned}
& \mu \text { Sedang }[8]=(8-4) /(11-4) \\
& =4 / 7 \\
& =0,6
\end{aligned}
$$

$\mu$ Sedang $[8]=(18-8) /(18-11)$ 


$$
=10 / 7
$$$$
=1,4
$$

Variabel Air Kran (Air Kran is Sedang)

$\mu$ Sedang $[40]=(50-20) /(40-20)$

$$
\begin{aligned}
& =(30) /(20) \\
& =1,5
\end{aligned}
$$

$\mu$ Sedang $[40]=(50-40) /(80-50)$

$$
\begin{aligned}
& =(10) /(30) \\
& =0,3
\end{aligned}
$$

[R1] : If ( Tinggi Air is Sedikit ) and ( Air Kran is Sedikit ) then ( Tingkat Pengisian is cepat). $\alpha$-predikat $1=\min (\mu$ Sedikit $(0,3), \mu$ Sedikit $(0,25)$

$$
=\min (0,3,0,25)=0,25
$$

$\left(\mathrm{Z}_{1}-100\right) / 200=0,25$

$\mathrm{Z}_{1}-100=0,25 * 200$

$\mathrm{Z}_{1}=50+100=150$
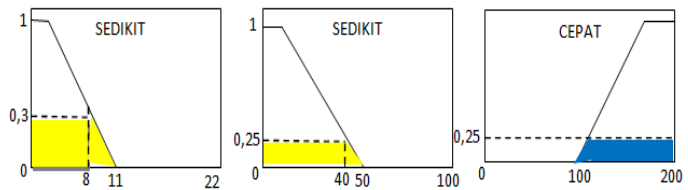

Gambar 9 Agregation Rule 1

[R2] : If (Tinggi Air is Sedikit) and (Air Kran is Sedang) then (Tingkat Pengisian is Cepat).

$\alpha$ - predikat $_{2}=\min (\mu$ Sedikit $(0,3), \mu \operatorname{Sedang}(0,3)$

$=\min (0,3,0,3)=0,3$

$\left(\mathrm{Z}_{2}-100\right) / 200=0,3$

$\mathrm{Z}_{2}-100=0,3 * 200$

$\mathrm{Z}_{2}=60+100=160$
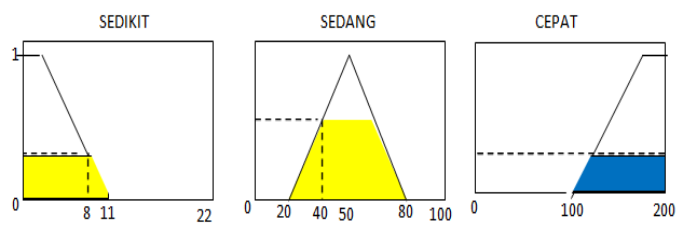

Gambar 10 Agregation Rule 2

[R4] : If (Air is Setengah) and (Kran is Sedikit) then (Tingkat Pengisian is Normal).

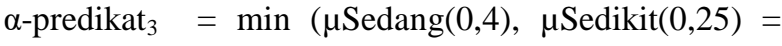

$\min (0,4,0,25)=0,25$

$\left(\mathrm{Z}_{3}-40\right) / 160=0,25$

$\mathrm{Z}_{3}-40=0,25 * 160$

$Z_{3}=40+40=80$
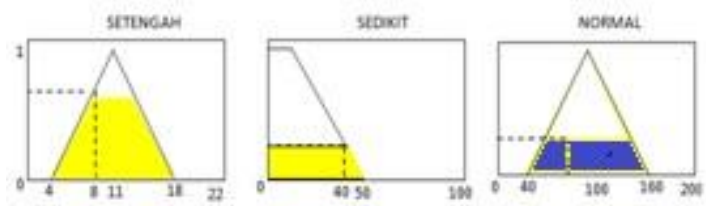

Gambar 11 Agregation Rule 4
[R5] : If (Air is Setengah) and (Air Kran is Sedang) then (Tingkat Pengisian is Normal).

$\alpha$-predikat $4=\min (\mu$ Sedang $(0,6), \mu$ Banyak $(0,3)$

$=\min (0,6,0,3)$

$=0,3$

$(\mathrm{Z} 4-40) / 160=0,3$

$\mathrm{Z} 4-40=0,3 * 160$

$\mathrm{Z} 4=48+40=88$
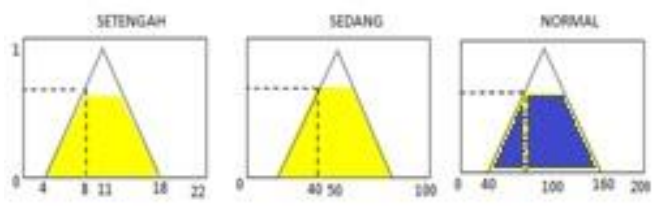

Gambar 12 Agregation Rule 5

Maka didapat daerah solusi Fuzzy variabel Tingkat Pengisian volume air yang normal seperti ditunjukkan pada gambar 13.

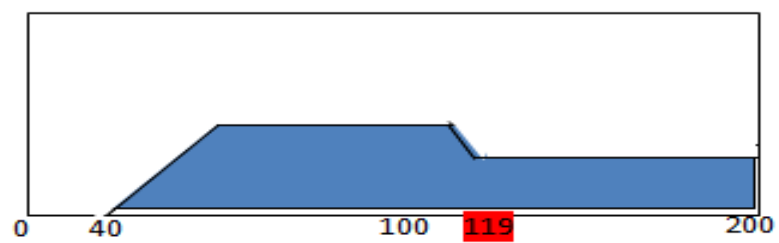

Gambar 13 Daerah Solusi Tingkat Pengisian Volume Air

Input dari proses Defuzzifikasi adalah suatu himpunan Fuzzy yang diperoleh dari komposisi aturan Fuzzy, sedangkan output yang dihasilkan merupakan suatu bilangan tegas pada domain himpunan Fuzzy tersebut. Sehingga jika diberikan suatu himpunan Fuzzy dalam range tertentu, maka harus dapat diambil suatu nilai crisp tertentu sebagai output. Defuzzyfikasi yang digunakan dalam menentukan tingkat pengisian volume air adalah dengan metode centroid.Berdasarkan daerah solusi Fuzzy tersebut, akan dihitung Tingkat pengisian sebagai keluaran himpunan tegas dari proses Defuzzifikasi dengan hasil sebagai berikut :

$$
\begin{gathered}
Z=\frac{\left(\alpha_{1} \times z_{1}\right)+\left(\alpha_{2} \times z_{2}\right)+\left(\alpha_{3} \times z_{3}\right)+\left(\alpha_{4} \times z_{4}\right)}{\left(\alpha_{1}\right)+\left(\alpha_{2}\right)+\left(\alpha_{3}\right)+\left(\alpha_{4}\right)} \\
=\frac{(0,25 * 150)+(0,3 * 160)+(0,25 * 80)+(0,3 * 88)}{0,25+0,3+0,25+0,3}
\end{gathered}
$$$$
Z=131,9 / 1,1=Z=119
$$

Jadi hasil dari himpunan tegas di atas menyatakan Tingkat Pengisian volume air $=119$ dari hasil perhitungan di atas dapat dilihat dari daerah solusi keanggotaan Fuzzy maka Tingkat pengisian $=119$ termasuk ke dalam kategori NORMAL.

\section{Kesimpulan}

Dari hasil pengujian pada tesis ini, dapat diambil kesimpulan dalam penentuan status tingkat pengisian volume air dalam tangki, yaitu : Perancangan alat 
pendeteksi volume air pada tangki air menggunakan ultrasonic HC-SR04 dapat mendeteksi tinggi air dalam tangki juga dapat menentukan status tingkat pengisian pada tangki hasilnya Mempermudah dalam memperoleh informasi banyak atau sedikitnya air di dalam tangki tersebut. Kemudian Pada perancangan alat ini system mampu berkerja secara akurat dengan input tinggi air dan keluaran air melalui kran serta pengujian pada matlab dapat menentukan tingka tpengisian yang dilihat dari rule - rule yang di rancang. Penerapan Fuzzy Logic dengan menggunakan matlab 7.1 yang dihubungkan dengan alat dapat memvisualisasikan hasil 3 (tiga) tingkat pengisian 1 . lambat 2. sedang dan 3. cepat. Komuniikasi antara interface dan mikrokontroller arduino uno pada system pendeteksi tinggi air sudah dapat berkomunikasi sesuai yang diinginkan.

\section{Daftar Rujukan}

[1] Getu dan Attia, 2016 . Automatic Water Level Sensor and Controller System, pp 1-5.
[2] Zhang, 2013 Research on Automatic Water level Detection Technique and Its Application for Open Water-replenishing tank of Central Air Conditioning, pp 1-6.

[3] Shah dkk, 2017 IoT based Smart Water Tank with Android application, 1-7.

[4] Crus dkk, 2017. Fuzzy-based Decision Support System for Smart Farm Tangki air Monitoring and Control, pp 1-5.

[5] Evelia dkk , 2013. Ant Colony Optimization for Membership Function Design for a Tangki air Fuzzy Logic Controller, pp 2732.

[6] zain dan Surmayanti, 2016 Perancangan Sistem buka tutup pintu air otomatis dimuara/waduk menggunakan sensor infrared dan photodioda dengan tampilan LCD berbasis arduino uno Atemega-328, pp 67-72.

[7] Thakur A.S dkk 2015.Designing of Fuzzy Logic controller for Liquid Level Controlling, pp 267-276.

[8] Nugroho G.P dkk 2013 . Sistem Pendeteksi Dini Banjir Menggunakan Sensor Kecepatan Air dan Sensor Ketinggian Air pada Mikrokontroler Arduino, pp 2301-9271.

[9] Gama L.A, 2016 Design of a water tanks monitoring system based on mobile devices, international conference on mechatronics, electronics and automotiveengineering, pp 133138

[10] Noach, F.P., fuzzy expert system penyakit scabies pada kambing,pp.55-66. 